GURSKI, R.; DALPIAZ, S.; VERDI, M. S. (orgs.)

\title{
Modernidade e Transmissão Simbólica
}

\author{
Sobre o livro: Cenas da infância atual:
}

a família, a escola e a clínica

ljuí, RS: Ed. Unijuí, 2006

Douglas Emiliano Batista

$\mathbf{u}$

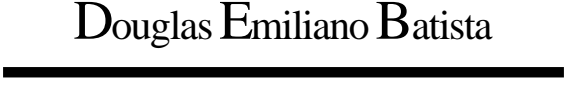

4

oi em comemoração ao quinto ano de atividade institucional da Clínica Maud Mannoni que em maio de 2003 ocorreu na cidade de Porto Alegre a Jornada de Estudos intitulada "Cenas da infância atual - a família, a escola e a clínica".

Tal jornada - a primeira promovida pela Clínica porto-alegrense - recebeu mais de trezentos participantes dentre psicólogos, educadores, psiquiatras, psicanalistas e fonoaudiólogos. A reunião de tantos especialistas - e em particular de alguns conferencistas que se empenharam em falar ao público a partir de um locus nem tão especializado assim - põe em relevo o espírito interdisciplinar do evento; evento durante o qual foram abordados, à luz não somente (muito embora, sobretudo) do patrimônio transmitido por Maud Mannoni, temas basilares acerca da infância e da juventude em face da família, da escola e da clínica.

Dentre os inúmeros frutos da jornada destaca-se o livro homônimo, cujos capítulos os organizadores mantiveram em consonância com a ordem de apresentação dos trabalhos no evento. Tendo em vista, pois, a ampla gama temática que o livro encerra, gostaríamos de destacar na presente resenha dois temas oblíquos à coletânea de artigos e

Mestrando da Faculdade de Educação da USP (Fe-USP).

U 
que, embora estejam muito longe de exaurir a amplitude do leque temático, constituem, a nosso ver, tópicos basilares da especulação teórica, os quais de alguma forma interessam diretamente à educação e, indiretamente, à clínica.

\section{O esgotamento da narrativa educacional moderna}

No artigo "Sobre demandas da família e possibilidades da escola", Verdi (Gurski, Dalpiaz \& Verdi, 2006, pp. 103-112) traz a lume o debate sobre a exaustão do modelo escolar da Era Moderna em face dos novos modos de subjetivação marcados pela virtualidade, relativização de saberes, alta velocidade, pluralidade, etc. Distinguindo tal perspectiva da mera lamentação nostálgica com que os discursos escolares tentam atualmente dar conta do desinteresse do alunado em face dos estudos, o autor louva a disposição dos profissionais de escola; profissionais que enfrentam a angústia relativa à assunção de um não-saber acerca das novas subjetividades emergentes e que se abrem à incerteza e à singularidade das múltiplas narrativas da Cultura contemporânea. É que a escola da Era Moderna - constituída num tempo de fé no progresso e na ciência - teria centralizado o saber e a sua transmissão, instituindo o entorno escolar sob a égide do não-saber, o que por fim perturbou a filiação simbólica.

Não obstante essa interpretação não possa ser desconsiderada, pensamos, entretanto, que com respeito ao processo de escolarização levado a cabo nos tempos modernos seja preciso não perder de vista outra importante faceta. Como diz Lajonquière (2000), foi a moderna obrigatoriedade de instrução pública e escolar das crianças que acabou por resguardar a filiação simbólica ante os caprichos patriarcais. Uma vez que a "escola da República" passou a educar as crianças em nome do soberano (entendido modernamente - isto é, de acordo com o espirito das leis - como o povo), a educação principiou a ocorrer então em nome dos pais; estes, por sua vez, entregavam as crianças aos cuidados da escola em nome de uma instância que os excedia, o que por fim demarcava o assujeitamento parental à Lei simbólica (em que pese, claro, que nenhum código positivo chegue de fato a encarnar a Lei; para dizê-lo em outras palavras: o autor avança a hipótese de o espirito das leis ser admitido como a moderna figuração da Lei simbólica). Tal obrigatoriedade escolar de instrução leiga, pública e gratuita dos recém-chegados - e de quem mais, afinal, poderia se tratar quando o assunto é educação? - teve sua contrapartida na elevação da esfera política a uma nova dignidade na aurora dos tempos modernos (Arendt, 1992, p. 
110). Não era então por outro motivo que, como explica Franklin Leopoldo e Silva (Silva, 2001), os iluministas compreendiam o tempo futuro como o tempo forte da humanidade: aos olhos dos homens do Esclarecimento, era, pois, no tempo presente que se deliberavam pela via política - e em face do que o passado legara possíveis rumos futuros para a vida na polis moderna. Tal densidade política atribuída ao presente viria, entretanto, a ser obliterada tempos mais tarde, quando o tecnicismo (e depois a tecnocracia) impôs hegemonicamente a crença no progresso e no desenvolvimento como uma adaptação inelutável a um 'futuro' conhecido de antemão. É, pois, sobretudo a isso que atribuímos a desautorização crescente dos sujeitos em face da transmissão simbólica de suas experiências (vejase a esse respeito o item II), mais do que, como se tornou praxe dizer, ao ideário da revolução francesa. Não é para menos, aliás, que o predicativo de "herdeiras paradoxais do ideário iluminista" (Lajonquière, 2003, p. 145) caiba com justiça às psicologias do desenvolvimento; o que no mais implica que a contemporânea anomia simbólica não é então um "desfecho necessário do projeto de vida moderno, articulado em torno da declinação social da imago paterna" (Lajonquière, 2000, p. 51). Essa anomia pode ser reconhecida, sobretudo - e sem que se abra mão de admitir os efeitos da última -, como um desdobramento da obliteração do espírito das leis, a qual está referida ao posicionamento inconsciente dos "herdeiros paradoxais" em vista dos Pais fundadores da polis moderna.
Pensando então a Ilustração a partir de um duplo prisma segundo o qual os paradoxos da modernidade (isto é, a dialética do esclarecimento) saltam aos olhos (Habermas, 2000, p. 470), não seria tanto o caso, afinal, de se deixar para trás a narrativa escolar da Era Moderna quando o objetivo é o de superar os impasses atuais da educação; trata-se, antes, de retomar o projeto de escolaridade pública, leiga e gratuita ou, ainda, no caso específico de nosso país, de chegar a implantá-lo aqui. É à luz disso que compreendemos a problemática apontada com razão por Verdi (Gurski et al., 2006, pp. 103-112), com respeito ao laço perverso que atualmente cinge os pais à escola: os pais (como "clientes exigentes") reconhecem que a escola possui o saber sobre as pretensas necessidades dos alunos, na exata medida em que isso representa a garantia de satisfação narcísica dos próprios pais que, pela educação, assegurariam o 'futuro' êxito individual de seus filhos. Certamente que em meio a tanta satisfação imediata é a escola que fica interditada de acenar com uma promessa de gozo no futuro (por sinal, o mesmíssimo tempo forte do iluminismo, isto é, um tempo futuro que, não deixando de ser ilusivo, é, contudo, estruturador)1. Eis que é no mínimo intrigante o modo como o paradigma pertinente à "escola de pais" - sob os imperativos de mercado - difundiu-se generosamente em nosso país (embora de modo algum esteja restrito a ele); ou, por outro lado, como se irradia - ainda que sob "argumentos inovadores, emancipadores" (Lefort, 1999, p. 218) - a idéia de uma suposta adequa- 
ção escolar aos 'novos valores' referidos à chamada pós-modernidade2. O mais paradoxal nisso tudo, entretanto, estriba-se no fato de que até mesmo um europeu neoconservador como Lipovetsky - para quem a atual apatia política promove a salvaguarda da esfera pública - reconheça que a 'lógica' sob a qual deve operar a escola é irredutível ao jogo de sedução e ao hiperinvestimento do tempo presente que marcam a cultura narcísica contemporânea (Lipovetsky, 1989, p. 18).

Tendo assim em vista "o conteúdo altamente ambivalente da modernidade cultural e social" (Habermas, 2000, p. 470) que faz coabitar em nosso tempo histórico emancipação e opressão, luzes e trevas (posto que o Esclarecimento - ao menos enquanto perdurar - será um processo não só inacabado como também inacabável, ou, em outras palavras, posto que toda clareagem inevitavelmente produz restos obscuros), não seria então imprudente alertar para o risco de incremento à banalização da cultura escolar encetado pela 'reciclagem' infrene dos saberes docentes ou pela abertura irrefletida aos modos alternativos de letramento e aos currículos multiculturalistas3. É certo que concordamos irrestritamente com o ideal antielitista da escola para todos, cf. Giordani (Gurski et al., 2006, pp.189-194). O que, no entanto, nos preocupa é que a chamada 'abertura curricular' ou a interlocução com as múltiplas línguas da cultura possa eventualmente dar margem, como não poucas vezes se tem visto, a que as escolas, por exemplo, introduzam em seu cotidiano - supondo-se mediante isso mais democráticas e plurais - laboratórios ou 'clínicas' de esqueite, de grafite, ou de fanzine, enquanto seus alunos continuam a se perfazer péssimos leitores, ou ignorantes em história, ou segregados no domínio das matemáticas. Por óbvio, não pensamos que em si mesmos os laboratórios constituam o ponto fulcral do problema; no entanto, indagamos se, em sentido propriamente ideológico, não será sobretudo de interesse do poder - ou mesmo uma astúcia sua, quiçá - a instituição de tal estado de coisas com respeito ao quadro curricular, de modo a forjar, mediante ele, "homens espiritualmente desarmados" (Lefort, 1999, pp. 221-23). Ou, em outros termos: não será, talvez, o caso de, no bojo mesmo do pós-iluminismo, encontrar-se afinal aninhado o contra-iluminismo (Habermas, 2000, p. 8), o que por fim concorre para a corrosão das possibilidades críticas com respeito ao poder estabelecido?

Ao dizer isso, estamos chamando atenção para o estofo simbólico (no sentido psicanalítico do termo) do ideal educacional da Era Moderna (em que pese o quão longe a escola no Brasil - mais ainda do que as escolas em muitos outros países - sempre esteve em face dele). Tal ideal exorta-nos ao impossivel (no estrito sentido freudiano) 
de sustentar a "relativa eqüidade na distribuição dos bens culturais" (Carvalho, 2004, p. 333), isto é, de ofertar condições escolares com vistas à aquisição por parte de crianças e jovens dos "pré-requisitos normais de um currículo padrão" (Arendt, 1992, p. 232)4. Em detrimento disso, as concepções pós-modernas (que a nosso ver fazem jus ao epíteto de "herdeiras paradoxais do iluminismo") acabam por embaraçar a compreensão do ato educacional como transmissão de marcas simbólicas (e, portanto, do estabelecimento de uma dívida simbólica por parte dos novos em relação aos velhos), o que rebaixa tal ato a uma suposta emancipação dos recém-chegados em vista do mundo antigo (Arendt, 1992, pp. 237-38). A dita 'abertura da escola para o mundo' costuma, pois, servir de corolário para que a transmissão do conhecimento do passado seja substituída pela reprodução bic et nunc do conhecimento do presente, senão do 'futuro' (Arendt, 1992, p. 232; Lefort, 1999, p. 218), como aliás não deixam de dar testemunho os laboratórios há pouco mencionados5. Por fim, também os discursos que apregoam sem mais a estetização do cotidiano escolar acabam incrementando a já inflada banalização do currículo, não obstante a relevância insofismável da Estética no tocante à formação espiritual dos mais novos. A 'estetização total' do cotidiano escolar não se confunde, entretanto, com a urgência de uma arte-da-infância que eduque 'artistando', cf. Corazza (Gurski et al., 2006. pp. 75-86), e que colabore para subtrair as crianças e os jovens da ecolalia das crenças (psico)pedagógicas e também do fardo imaginário com respeito à assunção de um suposto destino teleológico do desenvolvimento humano.

\section{O declínio do saber da experiência}

Não foram poucos os autores que chamaram atenção para o contemporâneo ocaso narrativo da experiência. Em particular, alguns deles trataram do ocaso das narrativas que educadores e psicanalistas como Makarenko, Freinet, Neill, Tosquelles e Mannoni levaram a cabo até meados do século XX. Tais narrativas educacionais foram sendo amiúde substituídas por medidas 'pragmáticas' e 'objetivas', como afirma Silva (Gurski et al., 2006, pp.115-122). E essa substituição não se deu por supostamente inexistirem hoje experiências institucionais férteis e proveitosas. Mas é que o reconhecimento da transitoriedade, da mutabilidade e da fluidez que caracterizam o campo educacional (deixando um espaço miúdo para as certezas) tem dado lugar a apostas instrumentais em torno do conhecimento tecnicista das instituições e dos dispositivos escolares 
(Baptista, pp. 197-202). Ao contrário disso, ao dialogar com as tradições educacionais legadas pelos educadores acima mencionados, Maud Mannoni deu a público o "vivido de uma instituição, o inacabamento de uma experiência" (Silva, p. 117), pondo em pauta a assunção de riscos e o desaferro à "regulamentação rígida" e ao "já dito" (Baptista, p. 201); isto é, afastando a pretensão de erigir leis que supostamente varressem em definitivo das instituições o erro.

A colonização da práxis educacional pelo cientificismo colaborou também para obliterar a fronteira que deveria demarcar as funções familiares das funções escolares. Paralelamente à regulação dos direitos infantis pelo Estado, a profusão do tecnicismo subtraiu à família parte de sua responsabilidade pelo bem-estar dos filhos (Gurski, pp. 95-102 ), o que então promoveu uma crescente desautorização por parte dos sujeitos em face da transmissão simbólica de suas experiências. E quando pais e professores suprimem as marcas subjetivas do ato educacional que veiculam, a legitimidade da transmissão da experiência do passado cai por terra, arrastando a possibilidade de sustentação da autoridade. Dado que o tempo contemporâneo está marcado pela aposta em um saber que provém de objetos pretensamente independentes da rede significante em que estão amealhados (Tavares, pp. 61-72), a busca por reconhecimento social a partir da posição de fora-da-lei - hoje aparentemente infrene - não pode deixar de refletir esse mesmo esvaziamento da experiência subjetiva e a conseqüente ausência de implicação por parte dos homens em face do seu destino em comum, isto é, em face do futuro.

Eis então que não basta à escola veicular um caudal de informações sob a presunção de que estas engendrem sentido por si mesmas (Folberg, pp. 217-222): ao contrário, é o simbolismo da função paterna que, creditando sentido aos discursos educacionais, consuma via Nome-do-Pai, a transmissão de valores que possibilitam a convivência ética como marca simbólica da existência humana. Não é então para menos (Fischer, pp. 27-40) que a mera profusão de informações pelo dispositivo midiático acabe engendrando subjetividades infantis resignadas e obedientes: o bebê consumidor, a criança-esperança, o adulto em miniatura, a menina culpada, enfim, todas essas figurações que capturam a infância "como um Outro a domar" (Fischer, p. 33). Eis que o espirito-criança (como abertura ao inaudito) declina a par e passo com o sentido da experiência, a qual poderia lançar-nos ao sabor da reinvenção da vida e do devir. Pelo contrário, o banho de imagens veiculado pela mídia retém a criança nas malhas da lição de moral, interpondo obstáculos à experiência de criar ('prima-irmã' da genuína experiência de ser). 
Encerrando então por aqui a presente resenha e tendo em vista os temas impreteríveis que foram abordados com agudeza de espírito ao longo do livro em tela (o qual mobilizou o legado mannoniano para com ele encetar novos inícios e novas possibilidades teóricas e institucionais), é que, ao cabo e ao fim, não se pode não recomendar francamente a sua leitura.

\section{REFERÊNCIAS BIBLIOGRÁFICAS}

Arendt, H. (1992). Entre o passado e o futuro (M. W. B. de Almeida, trad.). São Paulo: Perspectiva.

Carvalho, J. S. F. (2004). "Democratização do ensino" revisitado. Revista Educação e Pesquisa, 30 (2), 327-334.

. (1998). Apontamentos para uma crítica das repercussões da obra de Paulo Freire. Cadernos de História e Filosofia da Educação, 2 (4), 23-33.

Costa, J. F. (1988). Narcisismo em tempos sombrios. In J. Birman (Org.), Percursos na história da psicanálise (pp. 151-174). Rio de Janeiro: Livraria Taurus Editora.

Habermas, J. (2000). O discurso filosófico da modernidade (L. S. Repa \& R. Nascimento, trads.). São Paulo: Martins Fontes.

Lajonquière, L. (2000). Psicanálise, modernidade e fraternidade. In M. R. Kehl (Org.), Função fraterna (pp. 51-80). Rio de Janeiro: Relume Dumará.

(2003). A infância que inventamos e as escolas de ontem e hoje. Estilos da Clínica: Revista sobre a Infância com Problemas, 8 (15), 140-159.

A psicanálise e o debate sobre o desaparecimento da infância. Texto inédito.

Lefort, C. (1999). Formação e autoridade: a educação humanista. In C. Lefort, Desafios da escrita politica (E. M. de M Souza, trad., pp. 207-223). São Paulo: Discurso Editorial.

Lipovetsky, G. (1989). O império do efêmero: A moda e seu destino nas sociedades modernas (M. L. Machado, trad.). São Paulo: Companhia das Letras.

Silva, F. L. (2001). O mundo vazio: sobre a ausência da política no contexto contemporâneo. In D. A. Silva \& S. A. Marrach (Org.), Maurício Tragtenberg: Uma vida para as ciências humanas (pp. 239-250). Araraquara, S.P: Editora Unesp.

\section{NOTAS}

1 Jurandir Freire Costa trata da "ilusão estruturante de um futuro passível de ser libidinalmente investido" no artigo intitulado "Narcisismo em tempos sombrios" (Costa, 1988, p. 167).

$2 \mathrm{O}$ impossivel que marca o ofício ou o mister do educador não pode dizer respeito especificamente à emergência das novas gerações ditas pós-modernas, sob o risco de se re-introduzir com isso, mesmo que sob outros trajes, o problema da pretensa 'adequação' das intervenções educacionais ou pedagógicas a essas gerações 'pós-modernas'.

3 "É evidente que a escolha curricular dentre a diversidade dessas heranças [a saber, as heranças culturais de um país], bem como as práticas pedagógicas de que nos servimos para seu ensino, refletem uma divisão desigual de poder dentro da sociedade. É igualmente evidente que ela é passível de críticas e reformulações. Aliás, a própria continuidade de cada uma e do conjunto dessas heranças culturais implica modificações, posto que tudo aquilo que é vivo, não só biológica, mas também socialmente, modifica-se no transcurso do tempo. Mas elas sempre representarão as escolhas que o mundo adulto fez para transmitir às novas gerações" (Carvalho, 1998, p. 26). 
${ }^{4}$ Como assevera Carvalho, os conhecimentos escolares não são "uma síntese dos saberes universais. A bem da verdade, nem sequer sabemos se são os melhores ou os mais importantes, mas são aqueles que compõem o currículo escolar, que integram as instituições em que trabalhamos e são conhecimentos que de alguma forma valorizamos, escolar e socialmente". (Carvalho, 1998, p. 25-6). E mais: a autoridade do professor deriva, pois, "do fato de que ele é o agente institucional que inicia os jovens em uma série de valores, conhecimentos, práticas e saberes que são heranças públicas que uma nação escolheu preservar através de sua apresentação e incorporação por parte daqueles que são novos no mundo" (id., ib., grifo do autor).

5 Bem distinto disso é o que se passa nos ateliês de Bonneuil. Dubus (Gurski et al., 2006 , pp. 87-94) lembra que a 'brecha para o exterior' (marca de uma instituição estilhaçada) não prescinde da apropriação pelas crianças e jovens da interioridade dessa instituição, tarefa em vista da qual os ateliês de Bonneuil se destacam devido a sua regularidade $e$ a seus rituais sempre afiançados na e pela palavra e engajamento dos adultos.

demilian@uol.com.br

Recebido em abril/2007.

Aceito em maio/2007. 